\title{
Validation of the Brazilian version of the CP QOL-child for primary care givers proxy
}

\author{
Lígia MP Braccialli*, Ana C Braccialli, Michelle Z Silva, Adriana G Gonçalves and Andreia N Sankako \\ Docente do Departamento de Educacao Especial, Universidade Estadual Paulista, Marilia, Brasil
}

\begin{abstract}
Introduction: The child with cerebral palsy beyond the limitations of posture and movement may have innumerable other associates that influence performance in the functional abilities of daily life, that can have an impact on the quality of life. Assessing quality of life for children with cerebral palsy is important for achieving rehabilitation goals and participation. Currently, there are few specific instruments for assessing the quality of life of children with cerebral palsy, mainly in the Brazilian Portuguese.
\end{abstract}

Objective: This study aimed to assess the reliability and validity of the primary caregiver version of the Quality of Life Questionnaire for Children with Cerebral Palsy (CP QOL-CHILD) translated into Portuguese and culturally adapted for Brazil.

Method: A methodological study was carried out. The translated questionnaire was completed by 130 caregivers of children with cerebral palsy from different regions of the Brazil. The psychometric properties were evaluated in terms of test-retest reliability and internal consistency. The convergent validity was examined by calculating Pearson correlation coefficients for the questionnaire scores and the validated Brazilian versions of KIDSCREEN-10 and the Child Health Questionnaire.

Results: The results showed that the internal consistency values ranged from 0.76 to 0.90 , and the test-retest reliability values ranged from 0.74 to 0.81 . The instrument correlated with variables of the Child Health Questionnaire.

Conclusion: The Brazilian version of the CP QOL-CHILD for primary care givers proxy demonstrated adequate reliability and validity.

\section{Introduction}

There is a current concern about the quality of life of children with cerebral palsy (CP), in this sense, it is necessary to make available a validated instrument in Portuguese language developed specifically for this population, due to the characteristics of the disability, with content and language appropriate to the child's experience and development. CP is considered the most common cause of motor disability during childhood [1-3] with incidence rates of 2-2.5 / 1000 live births in developed countries [4,5] and 7 / 1000 live births in Brazil [6]. In spite of medical treatment and rehabilitation, motor limitations caused by by $\mathrm{CP}$ may result in changes of tone and posture, reducing functionality, motor skills [7], health [8] and quality of life of children with CP [9]. Because CP can have deleterious effects on functionality and communication during the performance of daily life activities damaging the independence, autonomy and quality of life (QOL) of involved children. The QOL for children may be influenced by cultural and environmental factors as well as beliefs and as such identication of a culturally adapted instrument is important in order to promote public policy actions for corresponding health and the education. Because generic instruments have limitations, there is a need to develop and use specific tools validated for that purpose [11].

A specific instrument to measure the quality of life of children with $\mathrm{CP}$ should address the patients' feelings about their adaptive equipment and the medical, therapeutic and surgical interventions performed [7] as well as the patients' satisfaction concerning access to services, availability of assistive technology resources, and patients' perceived acceptance within the community [12]. The World Health Organization recommends that measures of the quality of life of children, whenever possible, should be self-reported; however, concern exists that children's reports may be unreliable due to development problems, young age of the children, severity of illness, disability, cognitive deficits. When children cannot perform self-reports, parents can assess QOL via proxy so long as they have thorough and factual knowledge about their children. It is widely recognized that both self- and parental proxy-reports can offer important complementary, although different, information about the quality of life of children [13,14].

The Quality of Life Questionnaire for Children with Cerebral Palsy (CP QOL-Child) is composed of 3 highlighted components. It is based on the International Classification of Functioning, Disability and Health, developed by international experts and recognised for importance of obtaining the views of the children and caregivers [15]. The questionnaire consists of two formats: the Primary Caregiver Questionnaire (4-12 years) and the Child Report Questionnaire (912 years). To ensure the clear diagnosis of $\mathrm{CP}$, the form completed by the caregivers can be used for children 4 years of age and older. Children older than 12 and the Child Report Questionnaire were not included in this study secondary to adolescence issues, such as body

*Correspondence to: Ligia Maria Presumido Braccialli, Docente do Departamento de Educacao Especial, Universidade Estadual Paulista, Marília, Brasil, E-mail: bracci@marilia.unesp.br

Key words: cerebral palsy, quality of life questionnaire for children with cerebral palsy (cp qol-child), translation

Received: August 02, 2018; Accepted: August 22, 2018; Published: August 25, 2018 
image, sexuality and pressure from school and employment [12]. The CP QOL-Teen was developed to assess the quality of life of adolescents with CP [16].

The CP QOL-Child for primary caregivers (4-12 years) is a standardised, validated instrument for assessing the quality of life of children with cerebral palsy that has demonstrated a high level of internal consistency $(0.74-0.92)$ and test-retest reliability (0.76-0.89) [15]. The adaption and adoptation of this instrument across languages and cultures has advantages: I) it provides a common instrument for assessing quality of life in different cultural contexts, II) it provides a standardized measures for use in international studies, III) it allows comparison between groups, IV) it is less costly and more time efficient than building a new QOL instrument [17]. The CP QOLChild for primary caregivers was translated into Brazilian Portuguese and culturally adapted [18]. This study's purpose is to determine the psychometric properties of the instrument.

\section{Methods}

The study is of the methodological type, characterized by the development, validation and evaluation of instruments and research methods

We initially asked the authors of the CP QOL-Child at the School of Health and Social Development at Deakin University, Victoria, Australia, for the authorisation to translate the instrument into Portuguese, adapt it to the cultural context and validate the new version.

The project was submitted to the Ethics in Research Committee of the Faculdade de Filosofia e Ciências, UNESP, in Marília, São Paulo state, Brazil, and it was approved (No. 278/2009).

\section{Participants}

The study included 130 male and female caregivers of children with CP. The criterion for inclusion was being a parent or primary caregiver of a child with CP aged 4-12 years. Those individuals who were excluded were caregivers of children who were ill at the time of data collection. The parents or guardians who agreed to participate signed an informed consent form.

\section{Procedures}

The validation process followed the recommendations of the authors [19]. Physiotherapists who care for children with CP in the North, Northeast, Midwest, Southeast and Southern Regions of Brazil were contacted, and 200 families with children diagnosed with CP were identified. The Physiotherapists first contacted the families to explain the purpose of the study and to determine interest in participating. The physiotherapists completed a protocol that contained questions about the socio-demographic characteristics of the families and the classification of the child's CP according to the Gross Motor Function Classification System (GMFCS).

The 3 measures used in this study were the CP QOL-Child for primary caregivers, KIDSCREEN-10, and Child Health Questionnaire (CHQ-PF50). We opted for the using the Brazilian versions of the Kidscreen-10 and CHQ- PF50 to carry out convergent validation of the CP QOL-Child for primary caregivers, because both were validated for the Portuguese language of Brazil [20,21], and were the instruments used to validation of the original CPQOL [15].

The CP QOL-Child for primary caregivers (4-12 years) has 66 questions and should be answered by the parents or caregivers of children with $\mathrm{CP}$. The questions ask the parents or caregivers to rate their perceptions of the quality of life of their child in the following domains: (a) social well-being and acceptance (SWA); (b) participation and physical health (PPH); (c) functioning (FU); (d) emotional wellbeing (EWB); (e) access to services (AS); (f) pain and impact of disability (PI), and (g) family health (FH). The KIDSCREEN-10 for parents consists of 10 items and provides a simple score on the health-related quality of life of children and adolescents (20) and has been validated for use with Brazilian children (21). The Child Health Questionnaire (CHQ-PF50) is a generic instrument to assess the quality of life of children and has adequate reliability and validity for use with Brazilian children with cerebral palsy [22].

We initially sent the version proxy of the CP QOL-Child for primary caregivers, the KIDSCREEN-10 and the CHQ-PF50 to 200 families, but only 150 families returned properly completed questionnaires. After one week, only the version proxy CP QOL-Child for primary caregivers was sent to 150 families. One hundred thirty (130) questionnaires were returned, and the data were entered into an SPSS Statistics version 19.0 spread sheet for the statistical analysis of the questionnaire and the scores in each domain.

\section{Statistical analysis}

A descriptive statistical analysis was performed on the demographics of the study population. The verification of the normality of numeric data was performed using the Shapiro-Wilk Test [23]. The intraclass correlation coefficient (ICC) and the Cronbach's alpha coefficient were used to evaluate the reliability and internal consistency of the instrument. The ICC is considered excellent when $\geq 0.75$, satisfactory when $0.4 \leq$ ICC $<0.75$ and poor when ICC $<0.4$ [24]. The result was considered significant at $p<0.05$. A Cronbach's alpha coefficient above 0.5 indicates an instrument with internal reliability [25]. The convergent validity was evaluated by analysing the relationship between the CP QOL-Child for primary caregivers, the KIDSCREEN-10 and the Child Health Questionnaire (CHQ-PF50) using Pearson's correlation coefficient. Analysis of the differences between the five levels of GMFCS was verified by testing one-way analysis of variance (ANOVA).

\section{Results}

Regarding the demographic characteristics of the participants, the majority of the respondents were females (91\%), usually mothers (85\%), who lived in southeastern Brazil (70\%) and had an elementary school education (54\%) (Table 1).

The reliability of the CP QOL-Child for primary caregivers- proxy was adequate, with a Cronbach's alpha coefficient greater than 0.5 for all domains (Table 2).

Positive correlation between social well-being and acceptance (SWA) domains; role/social limitations - emotional/behavioral (REB); role/social limitations - physical (RP); mental health (MH); parental impact - time (PT); family activities (FA); and family cohesion (FC). Functioning (FU) was positively correlated with global health (GGH) while participation and physical health (PPH) showed positive correlation with global health (GGH), role/social limitations - emotional/behavioral (REB), and role/social limitations - physical (RP). Emotional well-being (EWB) was positively correlated with mental health $(\mathrm{MH})$ while access to service (AS) showed positive correlation with role / social limitations - physical (RP) and family activities (FA). Pain and impact of disability (PI) was negatively correlated with global health (GGH), bodily pain /discomfort (BP), 
Table 1. Demographic characteristics Primary caregiver $(\mathrm{N}=130)$

\begin{tabular}{|c|c|}
\hline Variable & $\mathbf{N}(\%)$ \\
\hline \multicolumn{2}{|l|}{ Child Characteristics } \\
\hline Age (years) & $7.4 \pm 2.7$ \\
\hline $\begin{array}{c}\text { Gender } \\
\text { male }\end{array}$ & $85(65)$ \\
\hline female & $45(35)$ \\
\hline \multicolumn{2}{|l|}{ GMFCS level } \\
\hline I & $40(31)$ \\
\hline II & $26(20)$ \\
\hline III & $17(13)$ \\
\hline IV & $18(14)$ \\
\hline $\mathrm{V}$ & $29(22)$ \\
\hline \multicolumn{2}{|l|}{ Primary Caregiver Characteristics } \\
\hline Age (years) & $30.21 \pm 8.7$ \\
\hline \multicolumn{2}{|l|}{ relationship } \\
\hline Grand mother & $06(05)$ \\
\hline sister & $02(01)$ \\
\hline brother & $02(01)$ \\
\hline mother & $110(85)$ \\
\hline father & $10(08)$ \\
\hline \multicolumn{2}{|l|}{ level of education } \\
\hline illiterate & $04(03)$ \\
\hline Complete Elementary school & $70(54)$ \\
\hline Incomplete Elementary school & $14(11)$ \\
\hline Complete High school & $34(26)$ \\
\hline Incomplete High school & $04(03)$ \\
\hline Complete College & $04(03)$ \\
\hline \multicolumn{2}{|l|}{ Gender } \\
\hline Male & $14(11)$ \\
\hline Female & $116(89)$ \\
\hline \multicolumn{2}{|l|}{ Region } \\
\hline Southeast & $91(70)$ \\
\hline South & $8(06)$ \\
\hline Midwest & $11(08)$ \\
\hline Northeastern & $14(11)$ \\
\hline Northern & $06(05)$ \\
\hline
\end{tabular}

GMFCS: LEVEL I: Walks without Limitations; LEVEL II: Walks with Limitations; LEVEL III: Walks Using a Hand-Held Mobility Device; LEVEL IV: Self-Mobility with Limitations; May Use Powered Mobility; LEVEL V: Transported in a Manual Wheelchair

Table 2. Internal consistency, test-retest reliability

\begin{tabular}{|l|c|c|}
\hline Subscale CP QOL child & Cronbach's alpha & ICC (95\% CI) \\
\hline Social well-being and acceptance (12 items) & 0.87 & $0.79(0.71-0.86)$ \\
\hline Functioning (12 items) & 0.81 & $0.80(0.71-0.86)$ \\
\hline Participation and physical health (11 items) & 0.84 & $0.77(0.61-0.80)$ \\
\hline Emotional well-being (6 items) & 0.82 & $0.76(0.66-0.83)$ \\
\hline Access to service (12 items) & 0.90 & $0.81(0.72-0.86)$ \\
\hline Pain and impact of disability (8 items) & 0.85 & $0.75(0.64-0.82)$ \\
\hline Family health (4 items) & 0.76 & $0.74(0.64-0.82)$ \\
\hline
\end{tabular}

behavior (BE), mental health $(\mathrm{MH})$, and parental Impact - emotional (EP). Family health (FH) had positive correlation with mental health $(\mathrm{MH})$ is shown in table 3.

There were no significant correlations between the domains of the CP QOL-Child and the domains of the KIDSCREEN-10 (for all domains, $\mathrm{p}>0.05$ ) are shown in table 4.

Significant differences were found between the levels of the GMFCS for Family Functioning and Health Subscale (Table 5).

\section{Discussion}

The analysis of the psychometric properties of the Brazilian version of the CP QOL-Child for primary caregivers shows that the instrument is reliable and valid for assessing the quality of life of children with $\mathrm{CP}$ between 4 and 12 years of age. Similar to the results found by Waters et al. [15], the seven domains of the CP QOL-Child for primary caregivers showed little or no correlation with the Child Health Questionnaire (CHQ-PF50) and the KIDSCREEN-10. This result suggests that generic instruments may not be sensitive enough to detect the essential domains of the quality of life of children with CP. Thus, the CP QOL seems to be more sensitive than generic instruments for assessing the quality of life of children with CP because it addresses issues that are important to these individuals, such as access to services, availability of assistive technology resources and acceptance in the community [2].

A study conducted by Waters et al. [15] on the psychometric properties of the original CP QOL-Child for primary caregivers found similar results to this study for the internal consistency of the pain and impact of disability and family health domains. Waters et al. [15] also found lower values for the Cronbach's alpha coefficient for those two domains. Dmitruk et al. [26] to check the internal consistency of CPQOl, translated into Polish, found values for Cronbach's alpha coefficient between 0.77 and 0.8 . The results of these authors differ from ours mainly in relation to domain Participation and Physical Health, which found the worst result. The different results found by the authors may be due to the cultural, educational and health care differences existing in the different countries.

Although the ICCs for all domains varied from excellent to satisfactory in our study, the values obtained in our study were lower than those obtained by Waters et al. [15]. Two factors may have contributed to this discrepancy: (1) the educational level of our sample was lower, and (2) Brazil is a large country with cultural, social and educational differences within its population. Individuals with low levels of education usually have difficulty reading and comprehending concepts, which may have affected our results. Because of the low education of some participants, we may have obtained better results if the data were collected through interviews.

During the study, one concern was recruiting participants from different regions of Brazil to obtain a representative sample of the population; however, Brazil is a multicultural country with significant regional differences, which may have influenced the comprehension of the questions and the answers given by the participants [21].

The low value obtained for the test-retest ICC (0.74) for the family health domain can be justified by the financial and physical health and the work of the caregivers. Their situations can change within 14 days, which was the required time interval between the first and second evaluations. The well-being and self-esteem domain showed a value of 0.76; this domain also requires a subjective evaluation and may show abnormalities in a short space of time.

Regarding the comparison between the functional levels of children there was observed significant difference for the Functioning and Family health domains. Different results were observed by Dmutrick et al. [26] that found significant differences between the child's functional level and in areas such as social wellbeing and acceptance $(p=0.045)$, emotional wellbeing $(p=0.025)$, and pain and impact of disability ( $p$ $=0.033$ ).

Children with CP usually exhibit other changes, such as communication difficulties and cognitive impairment, besides movement and posture limitations. Thus, they are not always able to perform self-reports; thus, an instrument that can be answered by the children's parents or caregivers is advantageous. The parent/caregiver reports are essential for assessing the quality of life of children with developmental disabilities, whether they are physical, communicative, 
Table 3. Correlations between CP QOL -proxy and Child Health Questionnaire (CHQ-PF50)

\begin{tabular}{|c|c|c|c|c|c|c|c|c|c|c|c|c|c|c|c|}
\hline \multirow{2}{*}{ CP QOL-Child } & \multicolumn{15}{|l|}{ Child Health Questionnaire (CHQ-PF50) } \\
\hline & GGH & REB & $\mathrm{PF}$ & $\mathrm{RP}$ & $\mathrm{BP}$ & $\mathrm{BE}$ & GBE & MH & SE & $\mathrm{GH}$ & $\mathrm{CH}$ & $\mathrm{PE}$ & PT & FA & FC \\
\hline SWA & 0.091 & $0.344 *$ & 0.160 & $0.331 *$ & 0.277 & 0.274 & 0.198 & $0.431 *$ & 0.097 & 0.240 & 0.181 & 0.175 & $0.298 *$ & $0.335^{*}$ & $0.331 *$ \\
\hline FU & $0.326^{*}$ & 0.161 & 0.060 & 0.239 & 0.174 & -0.020 & 0.005 & 0.115 & -0.161 & 0.093 & 0.039 & -0.049 & 0.043 & 0.180 & 0.135 \\
\hline PPH & $0.327 *$ & $0.311^{*}$ & 0.200 & $0.373 *$ & 0.279 & -0.054 & -0.119 & 0.184 & 0.004 & 0.138 & -0.066 & 0.169 & -0.062 & -0.024 & 0.143 \\
\hline EWB & 0.169 & 0.169 & 0.121 & 0.194 & 0.194 & 0.267 & 0.262 & $0.373^{*}$ & 0.008 & 0.138 & 0.183 & 0.186 & 0.109 & -0.045 & 0.093 \\
\hline AS & 0.134 & 0.266 & 0.256 & $0.363^{*}$ & -0.014 & 0.018 & -0.048 & 0.013 & 0.014 & 0.210 & 0.067 & -0.086 & -0.185 & $0.317 *$ & 0.144 \\
\hline PI & $-0.359 *$ & 0.110 & 0.008 & 0.004 & $-0.398 *$ & $-0.429 *$ & -0.193 & $-0.403 *$ & -0.220 & -0.235 & -0.032 & $-0.308^{*}$ & -0.123 & -0.179 & -0.150 \\
\hline FH & 0.149 & -0.050 & 0.088 & 0.031 & 0.235 & 0.098 & 0.178 & $0.329^{*}$ & 0.087 & 0.084 & 0.226 & 0.030 & -0.243 & -0.009 & 0.268 \\
\hline
\end{tabular}

${ }^{*} p<0.05$; SWA: Social well-being and acceptance; FU: Functioning; PPH: Participation and physical health; EWB: Emotional well-being; AS: Access to service; PI: Pain and impact of disability; FH: Family health; GGH: General Health; REB: Role/Social Emotional/Behavioral PF: Physical Functioning; RP: Role/Social limitations -Physical; BP: Bodily Pain/ discomfort; BE: Behavior; GBE: Global Behavior; MH: Mental Health; SE: Self Esteem; GH: General Health Perceptions; CH: Change Health; PE: Parental Impact Emotional; Pt: Parental ImpactTime; FA: Family Activities; FC: Family Cohesion

Table 4. Correlations between CP QOL - proxy and Kidscreen 10

\begin{tabular}{|c|c|c|c|c|c|c|c|}
\hline & \multicolumn{5}{|c|}{ CP QOL-Child } \\
\hline Kidscreen 10 & SWA & FU & PPH & EWB & AS & PI & 0.068 \\
\hline KID & 0.210 & 0.276 & 0.203 & 0.217 & -0.235 & 0.163 \\
\hline & 0.172 & 0.069 & 0.187 & 0.158 & 0.664 \\
\hline
\end{tabular}

Table 5. Mean scores CP QOL-Child- Proxy, according the GMFCS level

\begin{tabular}{|c|c|c|c|c|c|c|}
\hline \multicolumn{7}{|c|}{ GMFCS Levels } \\
\hline Subscale CP QOL child & $\begin{array}{c}\text { I } \\
\text { Mean }( \pm S D)\end{array}$ & $\begin{array}{c}\text { II } \\
\text { Mean }( \pm \mathrm{SD})\end{array}$ & $\begin{array}{c}\text { III } \\
\text { Mean }( \pm \mathrm{SD})\end{array}$ & $\begin{array}{c}\text { IV } \\
\text { Mean }( \pm \mathrm{SD})\end{array}$ & $\begin{array}{c}\mathrm{V} \\
\text { Mean }( \pm \mathrm{SD})\end{array}$ & $\begin{array}{l}\text { Anova } \\
\text { p value }\end{array}$ \\
\hline $\begin{array}{l}\text { Social well-being and } \\
\text { acceptance }\end{array}$ & $75.71( \pm 8.9)$ & $77.12( \pm 9.4)$ & $73.51( \pm 15.4)$ & $68.42( \pm 9.7)$ & $77.06( \pm 12.3)$ & 0.8728 \\
\hline Functioning & $69.1( \pm 12.6)$ & $75.3( \pm 12.4)$ & $64.8( \pm 15.4)$ & $56.6( \pm 10.4)$ & $65.5( \pm 14.9)$ & $0.0156^{*}$ \\
\hline $\begin{array}{l}\text { Participation and } \\
\text { physical health }\end{array}$ & $71.7( \pm 13.4)$ & $67.3( \pm 11.3)$ & $67.3( \pm 17.9)$ & $58.3( \pm 18.3)$ & $65.9( \pm 20.6)$ & 0.1538 \\
\hline Emotional well-being & $82.01( \pm 10.2)$ & $77.78( \pm 12.5)$ & $88.75( \pm 13.6)$ & $73.66( \pm 11.3)$ & $77.88( \pm 18.2)$ & 0.3608 \\
\hline Access to service & $64.65( \pm 24.7)$ & $60.69( \pm 29.2)$ & $69.20( \pm 13.9)$ & $59.12( \pm 15.2)$ & $70.84( \pm 16.3)$ & 0.3808 \\
\hline $\begin{array}{l}\text { Pain and impact of } \\
\text { disability }\end{array}$ & $31.77( \pm 19.9)$ & $31.73( \pm 17.9)$ & $34.77( \pm 18.6)$ & $24.70( \pm 15.3)$ & $30.85( \pm 17.8)$ & 0.8905 \\
\hline Family health & $68.34( \pm 13.7)$ & $69.09( \pm 14.3)$ & $73.66( \pm 21.3)$ & $54.24( \pm 19.5)$ & $71.23( \pm 14.6)$ & $0.0306^{*}$ \\
\hline
\end{tabular}

* Significant differences

learning or cognitive disabilities. The parents/caregivers can provide more information about the health and welfare of these individuals, even though there is a potential risk of increasing the subjectivity of the findings by not using self-reports [10]. For White-Koning et al. [13], although self-report is primordial, parents' information can be used to evaluate their children's quality of life in situations where children are unable to express their feelings because of a deficiency in their functional abilities, given that they know their children very well [8].

\section{Limitations}

The study had three limitations in the selection of participants, despite the concern in selecting a representative sample of Brazilian children with $\mathrm{CP}$, there was a predominance of children with $\mathrm{CP}$ in level I by GMFCS, a large number of participants had low education and prevalence of participants of southeast Brazil.

\section{Conclusions}

The Brazilian version of the CP QOL-Child for primary caregivers has adequate psychometric properties, and makes it possible to measure the quality of life of children with $\mathrm{CP}$ from different regions of the country. The instrument is easy to apply and it could potentially be used in both clinical practice and scientific settings.

\section{Acknowledgment}

We thank Elizabeth Waters and her team for permission to translate and analyse the psychometric properties of the instrument and the National Council for Scientific and Technological Development $(\mathrm{CNPq})$ and Pró-Reitoria de Pesquisa UNESP provided financial support.

\section{References}

1. Msall ME, Park JJ (2008) Neurodevelopmental management strategies for children with cerebral palsy: optimizing function, promoting participation, and supporting families. Clin Obstet Gynecol 51: 800-815. [Crossref]

2. O'Shea TM (2008) Diagnosis, treatment, and prevention of cerebral palsy. Clin Obstet Gynecol 51: 816-828. [Crossref]

3. Paneth N (2008) Establishing the diagnosis of cerebral palsy. Clin Obstet Gynecol 51: 742-748. [Crossref]

4. Reddihough DS, Collins KJ (2003) The epidemiology and causes of cerebral palsy. Aust $J$ Physiother 49: 7-12. [Crossref]

5. Shimony JS, Lawrence R, Neil JJ, Inder TE (2008) Imaging for diagnosis and treatment of cerebral palsy. Clin Obstet Gynecol 51: 787-799. [Crossref]

6. Lima CLA, Fonseca LF (2004) Paralisia cerebral: neurologia, ortopedia, reabilitação Rio de Janeiro: Guanabara Koogan.

7. Carlon S, Shields N, Yong K, Gilmore R, Sakzewski L, et al. (2010) A systematic review of the psychometric properties of Quality of Life measures for school aged children with cerebral palsy. BMC Pediatr 10: 81. [Crossref] 
8. Vargus-Adams J (2005) Health-related quality of life in childhood cerebral palsy. Arch Phys Med Rehabil 86: 940-945. [Crossref]

9. Dickinson HO, Parkinson KN, Ravens-Sieberer U, Schirripa G, Thyen U, et al. (2007) Self-reported quality of life of 8-12-year-old children with cerebral palsy: a crosssectional European study. Lancet 369: 2171-2178. [Crossref]

10. Morales NM, Funayama CA, Rangel VO, Frontarolli AC, Araújo RR, et al. (2008) Psychometric properties of the Child Health Assessment Questionnaire (CHAQ) applied to children and adolescents with cerebral palsy. Health Qual life Outcomes 6: 109-118. [Crossref]

11. Tsoi WS, Zhang LA, Wang WY, Tsang KL, Lo SK (2012) Improving quality of life of children with cerebral palsy: a systematic review of clinical trials. Child Care Health Dev 38: 21-31. [Crossref]

12. Waters E, Maher E, Salmon L, Reddihough D, Boyd R (2005) Development of a condition-specific measure of quality of life for children with cerebral palsy: empirical thematic data reported by parents and children. Child Care Health Dev 31: 127-135. [Crossref]

13. White-Koning M, Arnaud C, Dickinson HO, Thyen U, Beckung E, et al. (2007) Determinants of child-parent agreement in quality-of-life reports: a European study of children with cerebral palsy. Pediatrics 120: 804-814. [Crossref]

14. Viehweger E, Robitail S, Rohon MA, Jacquemier M, Jouve JL, et al. (2008) Measuring quality of life in cerebral palsy children. Ann Readapt Med Phys 51: 119-137. [Crossref]

15. Waters E, Davis E, Mackinnon A, Boyd R, Graham HK, et al. (2007) Psychometric properties of the quality of life questionnaire for children with CP. Dev Med Child Neurol 49: 49-55. [Crossref]

16. Davis E, Mackinnon A, Davern M, Boyd R, Bohanna I, et al. (2013) Description and psychometric properties of the CP QOL-Teen: a quality of life questionnaire for adolescents with cerebral palsy. Res Dev Disabil 34: 344-352. [Crossref]
17. Guillemin F, Bombardier C, Beaton D (1993) Cross-cultural adaptation of healthrelated quality of life measures literature review and proposed guidelines. $J$ Clin Epidemiol 46: 1417-1432. [Crossref]

18. Braccialli LMP, Braccialli AC, Sankako AN, Dechandt MLC, Almeida VS, et al (2013) Quality of life questionnaire for children with cerebral palsy (CP QOL-Child): Translation and cultural adaptation for brazilian portuguese language. Journal of human growth and development 23: 1-7.

19. Waters E, Davis E, Boyd R, Reddihough D, Mackinnon A, et al. (2006) Cerebral palsy quality of life for children translation guidelines. Melbourne: Deakin University

20. Ravens-Sieberer U, Erhart M, Rajmil L, Herdman M, Auquier P, et al. (2010) Reliability, construct and criterion validity of the KIDSCREEN-10 score: a short measure for children and adolescents' well-being and health-related quality of life. Qual Life Res 19: 1487-500. [Crossref]

21. Guedes DP, Guedes JERP (2011) Tradução, adaptação transcultural e propriedades psicométricas do KIDSCREEN-52 para a população brasileira. Rev Paul Pediatr 29: 364-371.

22. Machado CS, Ruperto N, Silva CHM, Ferriane VPL, Roscoe I, et al. (2001) The Brazilian version of the Childhood Health Assessment Questionnaire (CHAQ) and the Child Health Questionnaire (CHQ). Clin Exp Rheumat 19: S25-S29. [Crossref]

23. Armitage P, Berry G (1997) Estadística para la investigación biomédica. (3 ${ }^{\text {rd }}$ edn) Madrid: Harcourt Brace.

24. Szklo R, Nieto FJ (2000) Epidemiology Beyond the Basis. ( $2^{\text {nd }}$ edn). Aspen Publications

25. Maroco, J, Garcia-Marques T (2006) Qual a fiabilidade do alfa de Cronbach? Questões antigas e soluções modernas? Laboratório de Psicologia 4: 65-90.

26. Dmitruk E, Mirska A, Kulak W, Kalinowska AK, Okulczyk K, et al. (2014) Psychometric properties and validation of the Polish CP QOL-Child questionnaire: a pilot study. Scand J Caring Sci 28: 878-884. [Crossref]

Copyright: (C)2018 Braccialli LMP. This is an open-access article distributed under the terms of the Creative Commons Attribution License, which permits unrestricted use, distribution, and reproduction in any medium, provided the original author and source are credited. 